\title{
УРОВЕНЬ ОБРАЗОВАНИЯ КАК ФАКТОР ДЕМОГРАФИЧЕСКОГО ПРОГНОЗА
}

\section{Рецензия на книгу «World Population \& Human Capital in the Twenty-First Century»}

\section{АЛЕКСЕЙ ЩуР}

\begin{abstract}
Книга посвящена вопросам прогнозирования численности и структуры населения Земли до конща ХХІ века. Рассматриваются как технические детали построения подобных демографических прогнозов, так и последствиям различных вариантов прогноза для будущих траекторий развития человечества. Особое внимание авторы уделяют уровню образования населения, важнейшей, по их мнению, составляющей человеческого капитала. При этом, как подчеркивается в книге, образовательная структура населения является не только производной от демографических изменений и скорости «экспансии образования» в различных регионах и странах мира, но и сама оказывает и будет оказывать существенное влияние на демографические процессы; именно в этом кроется ее определяюшие значение для населения нашей планеты в XXI веке.
\end{abstract}

Ключевые слова: прогнозы населения, уровень образования, смертность, рождаемость, миграчия.

Прогнозирование численности населения, его возрастного и полового состава считается одной из важнейших прикладных задач демографии. Демографические прогнозы, как правило, ложатся в основу всех других прогнозов развития человечества. Без знания численности населения тяжело представить экономические прогнозы или прогнозы антропогенного воздействия на природу. К преимуществам демографических прогнозов (кратко- и среднесрочных) перед многими другими видами прогнозов о человеке и социуме можно отнести и высокую степень инерционности чисел рождений и смертей, уже заложенную в возрастной структуре прогнозируемого населения.

В 2014 г. свет увидел фундаментальный труд, подготовленный сотрудниками Международного института прикладного системного анализа (IIASA) и центра изучения демографии и человеческого капитала Витгенштейна под редакцией Вольфганга Лутца (Wolfgang Lutz), Уильяма Бутца (William P. Butz) и Самира Кэйси (Samir KC), «Население мира и человеческий капитал в XXI веке» [Lutz, Butz, KC 2014] ${ }^{1}$. Представленная книга результат масштабной работы, цель которой ознакомить как экспертное сообщество, так и широкую публику, включая лиц, определяющих политику в области народонаселения, с возможными сценариями развития населения мира (стран, регионов, континентов) как с учетом прошлых тенденций, так и на основе экспертных оценок будущих траекторий рождаемости, смертности и миграции и анализа определяющих их факторов. Но, пожалуй, центральное место в книге отводится образованию как важнейшей демографической характеристике населения и интегральной части прогнозов его численности и структуры. АЛЕКСЕЙ ЕВГЕНЬЕВИЧ ЩУР (aschur@hse.ru), НАЦИОНАЛЬНЫЙ ИССЛЕДОВАТЕЛЬСКИЙ УНИВЕРСИТЕТ «ВЫСШАЯ
ШКОЛА ЭКОНОМИКИ», РОССИЯ.

РЕЦЕНЗИЯ ПОСТУПИЛА В РЕДАКЦИЮ В ФЕВРАЛЕ 2019 Г.

${ }^{1}$ Далее при цитировании или отсылке к этой книге будет даваться только номер страницы. 
Традиционно в демографии двумя главными (определяющими) характеристиками любой совокупности людей считают пол и возраст. Будучи биологически, а не социально детерминированными, они выступают в качестве объективных и независимых переменных, прямо и косвенно определяющих основные демографические процессы. Вольфганг Лутц и коллектив авторов бросают вызов устоявшемуся представлению. С одной стороны, отмечается, что категории возраста и пола не являются полностью свободными от влияния социума и других демографических переменных. И если обсуждению объективной или субъективной природы пола в данной книге не отводится существенного места, то категория возраста (а именно его временная и пространственная относительность) подробно освещена в главе 11, рассматривающей прогнозы «старения» мирового населения (изменение медианного и проспективного возраста [Sanderson, Scherbov 2008], порога старости, демографической нагрузки пожилыми). С другой стороны, сквозь всю книгу рефреном проходит мысль, что «уровень образования это не одна из многих социальноэкономических характеристик, но, наряду с возрастом и полом, один из важнейших источников эмпирически наблюдаемой неоднородности населения» [14-15]. Во второй главе приводится обзор литературы, утверждающий наличие функциональной причинноследственной связи между более высоким уровнем образования и более крепким здоровьем (и, как следствие, более низкой смертностью) для мужчин и женщин, более высоким уровнем образования и более низкой рождаемостью (по крайней мере, на протяжении демографического перехода) для женщин. Также отмечается, что категория уровня образования - единственная, кроме возраста и пола, отвечающая трем критериям ${ }^{2}$, согласно которым тот или иной параметр можно применять в качестве стандартного демографического измерения в анализе и прогнозах населения.

Такое пристальное внимание к уровню образования не случайно и, как нам кажется, оправданно. С одной стороны, как было убедительно показано в представленной книге, различные сценарии изменения уровня образования в конкретном населении одинаковых для каждого уровня образования прогнозах уровня смертности, рождаемости и миграции приводят в средне- и долгосрочной перспективе к, зачастую, совершенно различным численности населения и возрастной структуре. На уровне всей планеты уже к 2060 г. речь может идти о дельте в сотни миллионов человек (и почти в миллиард к 2100 г.), обусловленной лишь различной прогнозируемой образовательной структурой населения Земли.

С другой стороны, уровень образования важен не только как фактор, значительно влияющий на демографическое поведение человека, а значит, и на динамику численности населения. Имея существенное социальное и экономическое значение, он интересен и сам по себе, независимо от демографии и демографических прогнозов. Уровень образования напрямую влияет на экономический рост, производительность труда, неразрывно связан с развитием и продвижением демократических институтов; более образованные люди живут дольше, чаще пребывают в состоянии полного физического и психологического благополучия (т. е. более «здоровы»), позже «стареют», намного более приспособлены к негативным последствия природных катастроф, частота которых будет неизбежно

\footnotetext{
2 Данные критерии приведены в соответствующей главе [15]. 
возрастать в связи с изменением климата, они лучше адаптированы к моделям устойчивого развития.

Книга построена следующим образом. Первые шесть глав посвящены основным сценарным переменным (рождаемость, смертность, миграция, уровень образования), в них рассматриваются основные теории и определяются ключевые факторы, излагаются допущения, которые в дальнейшем положены в основу различных (альтернативных) вариантов прогноза. В основе этих допущений лежат результаты опросов сотен экспертов и пяти экспертных встреч на пяти континентах (метод «Дельфи»). Результаты опросов экспертов для каждой страны были не только систематизированы, но и получили точную количественную оценку (при заполнении анкеты эксперт должен был оценить вероятность наступления того иного события по шкале от нуля до единицы и его релевантность для прогнозируемого процесса по шкале от минус единицы до плюс единицы ${ }^{3}$; произведение двух этих значений - количественная оценка влияния того или иного события на уровень рождаемости, смертности, миграции). Такой подход к оценке экспертного мнения вкупе с подробным изложением и обоснованием главных сценарных демографических переменных выгодно отличает данный прогноз от большинства других прогнозов различных международных организаций, включая самый известный - прогноз отдела народонаселения ООН. Это стоит, безусловно, отнести к одному из главных достоинств представленной книги. В седьмой главе более детально описан механизм построения прогноза по полу, возрасту и уровню образования, в основе которого лежит когортно-компонентный метод. Последние главы посвящены анализу полученных результатов, в них отображены основные будущие тенденции развития мирового человеческого капитала, показано, каким образом изменение образовательной структуры населения планеты повлияет не просто на изменение численности населения Земли, но и на его многие «качественные» характеристики, о чем было вкратце сказано выше. Но, предостерегают авторы книги, оптимистический взгляд на будущее (стабилизация численности мирового населения, низкий уровень смертности, замедление или даже «разворот» старения населения в терминах проспективного возраста) возможен только, как минимум, при сохранении современных темпов роста уровня образования населения развивающихся стран. Консервация нынешней образовательной структуры населения мира значительно замедлит демографический переход, приведет к взрывному росту численности населения этих стран, сделает их более уязвимыми к различным внешним и внутренним шокам, усилит миграционное давление на развитые страны. В целом авторы книги с помощью математических методов прогнозирования показывают, как образование может и будет определять траектории развития человеческого капитала до конца века.

По моему мнению, представленная книга интересна как для демографов, так и для российского научного сообщества в целом. Сейчас в России при составлении прогнозов населения «уровень образования» как самостоятельная категория не рассматривается. Между тем добавление этой переменной могло бы повысить точность прогнозов и придать им большую функциональность. Правда, в условиях отсутствия регистра населения

\footnotetext{
3 Значение, равное 0 , означает полную нерелевантность, -1 - отрицательную связь, +1 - положительную связь.
} 
единственный достоверный источник сведений об образовательной структуре населения России - перепись; в такой ситуации прогнозирование уровня образования и оценка его влияния на различные демографические процессы (рождаемость, брачность, смертность, миграцию) значительно затруднены. Тем не менее, существует ряд исследований, показывающих значительное влияние уровня образования в России как на уровень рождаемости [Захаров 2016], так и на уровень смертности [Shkolnikov et al. 1998]. Так, например, разрыв в ожидаемой продолжительности жизни между наиболее и наименее образованными россиянами превышает 10 лет [Murphy 2006]. Особенно важно учитывать образовательную структуру в условиях ее сильной волатильности в поколениях, находящихся сейчас в репродуктивных возрастах, при прогнозировании коэффициентов суммарной рождаемости, принимая во внимание сильную степень неоднородности календаря рождений (средний возраст) у женщин, принадлежащих к различным образовательным категориям. Самостоятельный интерес представляет и прогноз изменения образовательной структуры населения России сам по себе. Часто полагают, что наша страна уже давно максимизировала образовательный компонент человеческого капитала, но представления, в том числе и в научной среде, о всеобщности высшего образования в России не слишком обоснованы [Бессуднов, Куракин, Малик 2017]. Россия по доле лиц с высшим образованием в молодых когортах находится на уровне своих восточноевропейских соседей, но уступает развитым западным и восточноазиатским странам. Базовый вариант прогноза (в основу которого положены текущие тенденции), представленный в рецензируемой книге, к сожалению, предполагает сохранение нашего отставания в уровне образования на протяжении всего XXI века. Учитывая сколь серьезную роль уровень образования играет и в демографических процессах, и в развитии экономики, было бы несколько опрометчиво и впредь не уделять большего, чем сейчас, внимания этой важнейшей характеристике населения в анализе и прогнозах населения.

\section{ЛИТЕРАТУРА}

Бессуднов А.Р., Куракин Д.Ю., Малик В.М. (2017). Как возник и что скрывает миф о всеобщем высшем образовании. Вопросы образования. 3, 83-109.

Захаров С.В. (Ред.) (2018). Население России 2016. Двадиать четвертый ежегодный демографический доклад. Москва: Издательский дом ВШЭ.

Lutz W., Butz W.P., KC S. (2014). World Population \& Human Capital in the Twenty-First Century. New York: Oxford University Press.

Murphy M., Bobak M., Nicholson A., Rose R., Marmot M. (2006). The widening gap in mortality by educational level in the Russian Federation, 1980-2001. American Journal of Public Health 96, 7, 1293-1299.

Sanderson W., Scherbov S. (2008). Rethinking age and aging. Population Bulletin, 63 (4).

Shkolnikov V., Leon D.A., Adamets S., Andreev E., Deev A. (1998). Educational level and adult mortality in Russia: an analysis of routine data 1979 to 1994. Soc Sci Med, 47, 357-369. 


\title{
EDUCATION LEVEL AS A FACTOR \\ IN DEMOGRAPHIC FORECASTING \\ Review of the book «World Population \& Human Capital in \\ the Twenty-First Century»
}

\section{ALEKSEI SHCHUR}

\begin{abstract}
The book is devoted to issues of forecasting the size and structure of the Earth's population until the end of the XXI century; it focuses on both the methodological aspects of making such demographic projections and on the consequences of various forecast scenarios for future trajectories of human development. The authors pay special attention to the level of education - in their opinion, the most significant component of human capital. At the same time, the educational structure of the population is not only a derivative of demographic changes and the pace of "education expansion" in various regions and countries of the world, but also itself has and will continue to have a significant impact on demographic processes. This is precisely the kind of defining impact education will have for the population of our planet in the 21 st century.
\end{abstract}

Key words: population projections, education levels, mortality, fertility, migration.

Aleksei Shchur (aschur@hse.ru), National Research University Higher School of Economics, Russia.

DATE RECEIVED : FEBRUARY 2019.

\section{REFERENCES}

Bessudnov A., Kurakin D., Malik V. (2017). The myth about universal higher education: Russia in the international context. Educational Studies. 3, 83-109. (In Russ.) doi: 10.17323/18149545-2017-3-83-109

Lutz W., Butz W.P., KC S. (2014). World Population \& Human Capital in the Twenty-First Century. New York: Oxford University Press.

Murphy M., Bobak M., Nicholson A., Rose R., Marmot M. (2006). The widening gap in mortality by educational level in the Russian Federation, 1980-2001. American Journal of Public Health 96, 7, 1293-1299.

Sanderson W., Scherbov S. (2008). Rethinking age and aging. Population Bulletin, 63 (4).

Shkolnikov V., Leon D.A., Adamets S., Andreev E., Deev A. (1998). Educational level and adult mortality in Russia: an analysis of routine data 1979 to 1994. Soc Sci Med, 47, 357-369.

Zakharov S.V. (Ed.) (2018). Russia's Population in 2016: 24rd Annual Demographic Report. Moscow: HSE Publishing House. (In Russ.) doi: 10.17323/978-5-7598-1772-7 